\title{
ASSESSMENT OF COMMONLY AVAILABLE ANTIMICROBIAL AGENTS. A STUDY FROM ILALA-TANZANIA.
}

\author{
By: Malaika Paul (B.PHARM4, MUHAS-2008/2009)
}

\section{ABSTRACT OBJECTIVE}

Microbiological assessment of commonly available antimicrobial agents in Ilala Municipality.

\section{METHODOLOGY}

The disc diffusion method was used for the determination of antimicrobial activities.

\section{RESULTS}

Amoxicillin exhibited ZI between $21 \mathrm{~mm}$ (Elys) and $23 \mathrm{~mm}$ (Zenufa) against $E$. coli, and between $21 \mathrm{~mm}$ and $23 \mathrm{~mm}$ (Elys) against S. aureus. Ampicillin samples yielded ZI from $20 \mathrm{~mm}$ (India) to $25 \mathrm{~mm}$ (Keko) against both bacteria. Dicloxacillin exhibited ZI between $13 \mathrm{~mm}$ (Keko) and $16 \mathrm{~mm}$ (India, Keko) against $E$. coli and from $15 \mathrm{~mm}$ (Keko) to $18 \mathrm{~mm}$ (Shelys) against S.aureus. Ciprofloxacin samples (India) exhibited ZI between $22 \mathrm{~mm}$ and $25 \mathrm{~mm}$ against both bacteria.

On the other hand ketoconazole exhibited ZI between 16.5 and $19.0 \mathrm{~mm}$ against both Candida albicans and Cryptoccocus neoformans. Nystatin (Cyprus) produced ZI between 10 and 12mm against both fungi; similarly Fluconazole (India) yielded between 16.5 and 20mm of ZI against both C. albicans and C. neoformans.

\section{CONCLUSION}

The antimicrobial agents analyzed in this study have demonstrated substantial antimicrobial activities against the test microorganisms, an indicative of possession of active ingredients.

As far as the in vitro microbiological assays are concerned, the study's findings could not reveal any counterfeit drug.

However, further studies should be conducted to confirm the content specifications and other relevant parameters of each pharmaceutical preparation.

\section{INTRODUCTION}

Antimicrobial sensitivity tests are performed to test on the effectiveness of antimicrobial agents against microorganisms. Some of the most common methods include serial dilution, ditch plate, cup plate and solid dilution. For the disc diffusion method, the drug inhibits the growth of microorganisms in the area around the disc across which the drug diffuses from the impregnated disc. The inhibition effect is measured as diameter or radius in millimeter (zone of inhibition).
Drugs which exhibit large zones of inhibition are described as effective against the specified microorganisms, those which exhibit small or no zones of inhibition are described as ineffective against the microorganisms (contain little or no active ingredients), such drugs may also be described as counterfeit antimicrobials.

Therefore antimicrobial sensitivity tests can be microbiologically used to screen for counterfeit antimicrobial agent.

According to World Health Organization (WHO) 
counterfeit medicines may include products with the correct ingredients but fake packaging, with the wrong ingredients, without active ingredients or with insufficient active ingredients. ${ }^{1}$

Counterfeit medicines represent an enormous public health challenge. Anyone, anywhere in the world, can come across medicines seemingly packaged in the right way, in the form of tablets or capsules that look right, but which do not contain the correct ingredients and, in the worst case scenario, may be filled with highly toxic substances. In some countries, this is a rare occurrence, in others, it is an everyday reality. ${ }^{1}$

Chemotherapeutic agents such as antibiotics, and antifungal agents are used for treating microbial diseases or infections.

The great demand of these medicines, poor regulatory authorities and corruption influence some pharmaceutical Industries to produce counterfeit antimicrobials. ${ }^{2}$ Other factors such as poor quality control during manufacture and climatic conditions (poor storage) also contribute to the prevalence of counterfeit medicines in the pharmaceutical market. ${ }^{1}$

Patients unknowingly use some of the counterfeit medicines which illegally enter into the Pharmaceutical market. The consumption of such products leads to undesired and unpredictable effects to patients, drug resistance and even death.

Therefore the antimicrobial sensitivity study could screen for the presence of such counterfeits in the market and share such information with the Tanzania Food and Drugs Authority for further investigations so as to protect the public from the fatal effects of such pharmaceutical products.

Drug counterfeiting is reported to be a worldwide problem with the developing countries exhibiting higher prevalence rates.

About $1 \%$ of medicine sales in developed and up to $10 \%$ of medicine sales in developing countries are counterfeit. ${ }^{1}$

About one third of the WHO member states have poor means of controlling counterfeit medicines while up to $10 \%$ of drugs in developed and up to $25 \%$ of drugs in developing countries are counterfeit drugs. ${ }^{2}$
For instance, during a meningitis epidemic in Niger in 1995 , more than 50,000 people were inoculated with fake vaccines resulting in 2500 deaths. ${ }^{1}$

In 2001, in South-East Asia, a Welcome Trust study revealed that $38 \%$ of 104 anti-malarial drugs on sale in pharmacies did not contain any active ingredients. ${ }^{1}$

In Cambodia, in 1999, at least 30 people died after taking counterfeit anti-malarials prepared with sulphadoxine-pyrimethamine (an older, less effective anti-malarial) which were sold as artesunate. ${ }^{1}$

According to a report released by the Organization for Economic Cooperation and development, $75 \%$ of counterfeits Worldwide come from India, some from Egypt and China. ${ }^{3}$

A recent report show that antibiotics, anti-malarials and antiviral agents are the most counterfeited medicines. ${ }^{1}$

It is also speculated that up to $40 \%$ of products labeled as containing artesunate (anti-malarial) contain no active ingredients and therefore have no therapeutic benefits. This is attributed to the counterfeiters' ability to reproduce holograms and other sophisticated printing techniques that had dramatically improved between 2001 and 2005, making detection even more difficult. $^{1}$

The Food and Drugs Authority (FDA) estimates that up to $15 \%$ of all sold medicines in the World are counterfeits and in some parts of Asia and Africa figures exceed $50 \%{ }^{4}$

The United Nations humanitarian news reported that the busy Kariakoo market in the Tanzanian capital is stocked with knock-off merchandise - from imported car parts to handbags - and traders from across Africa come to buy cheap imports to sell at home. But the most dangerous counterfeits are the imitation medicines sold to unwitting consumers. ${ }^{5}$

\section{METHODOLOGY}

The disc diffusion method was used for the determination of antimicrobial activities.

\section{MATERIALS}

Apparatus used: Universal bottles, incubator, autoclave, Petri dishes, flasks, pipettes, Bunsen burner, 
refrigerator, aluminium foil, and chemical balance.

Solvents used; Distilled water and dimethylsulfoxide (DMSO)

Media used were; Nutrient agar (NA) (Mumbai, India) and Sabouraud Dextrose agar (SDA) (Mumbai, India).

Test microorganisms; Standard strains of reference microorganisms;

Bacteria; E. coli and Staphyloccocus aureus

Fungi; Candida albicans and Cryptoccocus neoformans.

Antibiotics; Twenty samples of antibiotics (amoxicillin, ampicillin, dicloxacillin and ciprofloxacin).

Antifungal agents; Ten samples of antifungal agents (nystatin, ketoconazole and fluconazole).

\section{PROCEDURES}

\section{Collection Of Samples}

Twenty different types of antibiotics and ten samples of antifungals were randomly collected from different Pharmacies and Medical stores in Ilala Municipality.

The samples were weighed on electronic balance of which amoxicillin (250mg), ampicillin (250mg), dicloxacillin (250mg), ketoconazole (200mg), fluconazole (150mg) and nystatin (10mg) were separately suspended in $2.5 \mathrm{ml}$ of DMSO while $500 \mathrm{mg}$ of ciprofloxacin was suspended in $5.0 \mathrm{ml}$ of DMSO. About $20 \mu \mathrm{l}$ of each sample was impregnated on a $5 \mathrm{~mm}$ diameter wide disc and left to dry before being deposited onto agar plates inoculated with strains of reference microorganisms against E.coli and Staphyloccocus aureus (bacteria) and Candida albicans and Cryptoccocus neoformans (fungi). After an aerobic overnight incubation at 37 으, mean zones of inhibition (ZI) were determined and recorded in millimeters.

\section{Culture Media Preparation}

About $14 \mathrm{gm}$ of NA and $32.5 \mathrm{gm}$ of SDA were respectively weighed and put into different conical flasks then $500 \mathrm{ml}$ of distilled water were added in each flask to form suspensions which were sterilized in an autoclave at $121 \stackrel{\circ}{ } \mathrm{C}$. The resulting hot solution was poured into Petri dishes and allowed to solidify at room temperature, after solidification the Petri dishes with the agar were refrigerated at about $4{ }^{\circ} \mathrm{C}$ for about 12 hours.

\section{STOCK SOLUTION PREPARATION}

About 250mg of each of the collected antimicrobial agents namely amoxicillin, ampicillin and dicloxacillin was dissolved in $2.5 \mathrm{ml}$ of DMSO, while $500 \mathrm{mg}$ of ciprofloxacin was dissolved in $5.0 \mathrm{ml}$ of DMSO.

Ketoconazole (200mg), fluconazole (150mg), and nystatin (10mg) were weighed and separately dissolved in $2.5 \mathrm{ml}$ of DMSO.

\section{PREPARATION OF ANTIMICROBIAL DISCS}

Several discs were punched out from a sheet of Whatmann filter paper and each disc was impregnated with $20 \mu$ l of the stock solution and then dried ready for use.

\section{ANTIMICROBIAL ACTIVITIES TESTING}

Two discs of each drug sample were tested for antibacterialactivitiesagainst E.coliandStaphyloccocus aureus, while for antifungal activities Candida albicans and Cryptoccocus neoformans were employed as test microorganisms.

The inoculated Petri dishes with the test antimicrobial discs were incubated at $370 \mathrm{C}$ overnight and on the next day mean zones of inhibition were determined, recorded and interpreted accordingly. 


\section{RESULTS}

Table 1: Analyzed samples of antimicrobial agents

\begin{tabular}{|c|c|c|c|c|c|c|}
\hline \multirow[t]{2}{*}{ Sample } & \multirow[t]{2}{*}{ Name } & \multirow[t]{2}{*}{ Source } & \multicolumn{4}{|c|}{ Mean ZI (mm) } \\
\hline & & & E. coli & S. aureus & C.albicans & C.neoformans \\
\hline S1 & Amoxicillin & Elys & 21.0 & 21.0 & ND & ND \\
\hline S2 & Amoxicillin & Zenufa & 22.0 & 23.0 & ND & ND \\
\hline S3 & Amoxicillin & Elys & 21.0 & 23.0 & ND & ND \\
\hline S4 & Amoxicillin & Zenufa & 23.0 & 21.0 & ND & ND \\
\hline S5 & Amoxicillin & India & 22.0 & 21.0 & ND & ND \\
\hline S6 & Ampicillin & India & 22.0 & 20.0 & ND & ND \\
\hline S7 & Ampicillin & Shelys & 21.0 & 24.0 & ND & ND \\
\hline 58 & Ampicillin & Keko & 24.0 & 25.0 & ND & ND \\
\hline S9 & Ampicillin & Shelys & 23.0 & 22.0 & ND & ND \\
\hline S10 & Ampicillin & India & 24.0 & 23.0 & ND & ND \\
\hline S11 & Ciprofloxacin & India & 22.0 & 22.0 & ND & ND \\
\hline$S 12$ & Ciprofloxacin & India & 23.0 & 24.0 & ND & ND \\
\hline$S 13$ & Ciprofloxacin & India & 24.0 & 23.0 & ND & ND \\
\hline S14 & Ciprofloxacin & India & 22.0 & 24.0 & ND & ND \\
\hline S15 & Ciprofloxacin & India & 23.0 & 25.0 & ND & ND \\
\hline S16 & Dicloxacillin & Keko & 16.0 & 16.0 & ND & ND \\
\hline S17 & Dicloxacillin & Shelys & 15.0 & 18.0 & ND & ND \\
\hline S18 & Dicloxacillin & Keko & 13.0 & 15.0 & ND & ND \\
\hline S19 & Dicloxacillin & Shelys & 14.0 & 17.0 & ND & $\mathrm{ND}$ \\
\hline S20 & Dicloxacillin & India & 16.0 & 15.0 & ND & ND \\
\hline$S 21$ & Ketoconazole & Cyprus & ND & ND & 18.5 & 19.0 \\
\hline$S 22$ & Ketoconazole & Microlabs & ND & ND & 18.0 & 18.5 \\
\hline 523 & Ketoconazole & Cyprus & ND & ND & 16.5 & 17.5 \\
\hline S24 & Nystatin & Cyprus & ND & ND & 10.0 & 11.5 \\
\hline $\mathbf{S 2 5}$ & Nystatin & Cyprus & ND & ND & 12.0 & 12.0 \\
\hline$S 26$ & Nystatin & Cyprus & ND & ND & 11.0 & 12.0 \\
\hline S27 & Fluconazole & India & ND & ND & 17.0 & 16.5 \\
\hline S28 & Fluconazole & India & ND & ND & 16.5 & 19.5 \\
\hline S29 & Fluconazole & India & ND & ND & 19.5 & 19.5 \\
\hline $\mathbf{S 3 0}$ & Fluconazole & India & ND & ND & 18.5 & 20.5 \\
\hline
\end{tabular}

$N D=$ not done.

Table 2: Samples by respective sources/manufacturers

\begin{tabular}{|l|l|l|l|l|l|l|l|c|}
\hline & \multicolumn{7}{|c|}{ Manufacturer } & Total \\
\cline { 2 - 9 } & Elys & Zenufa & India & Shelys & Keko & Cyprus & Microlabs & \\
\hline Amox & 2 & 2 & 1 & - & - & - & - & 5 \\
\hline Amp & - & - & 2 & 2 & 1 & - & - & 5 \\
\hline Cipro & - & - & 5 & - & - & - & - & 5 \\
\hline Diclox & - & - & 1 & 2 & 2 & - & - & 5 \\
\hline Ketaco & - & - & - & - & - & 2 & 1 & 3 \\
\hline Nysta & - & - & - & - & - & 3 & - & 3 \\
\hline Flucon & - & - & 4 & - & - & - & - & 4 \\
\hline Total & $\mathbf{2}$ & $\mathbf{2}$ & $\mathbf{1 3}$ & $\mathbf{4}$ & $\mathbf{3}$ & $\mathbf{5}$ & $\mathbf{1}$ & $\mathbf{3 0}$ \\
\hline
\end{tabular}


Table3: Means of $\mathrm{Zl}$ yielded by test microorganisms against drug samples

\begin{tabular}{|c|c|c|c|c|}
\hline Microbe & Drugs & Conc. (mg) & Manufacturer & Mean ZI (mm) \\
\hline \multirow[t]{10}{*}{ ST } & \multirow[t]{3}{*}{ AMOX } & \multirow{3}{*}{2.0} & Elys & 22.0 \\
\hline & & & Zenufa & 22.0 \\
\hline & & & India & 21.0 \\
\hline & \multirow{3}{*}{ AMP } & \multirow{3}{*}{2.0} & India & 21.5 \\
\hline & & & Shelys & 23.0 \\
\hline & & & Keko & 25.0 \\
\hline & CIPRO & 2.0 & India & 23.6 \\
\hline & \multirow[t]{3}{*}{ DIC } & \multirow[t]{3}{*}{2.0} & India & 15.0 \\
\hline & & & Shelys & 15.5 \\
\hline & & & Zeko & 17.5 \\
\hline \multirow[t]{10}{*}{ EC } & \multirow[t]{3}{*}{ AMOX } & \multirow[t]{3}{*}{2.0} & Elys & 21.0 \\
\hline & & & Zenufa & 22.0 \\
\hline & & & India & 22.0 \\
\hline & \multirow[t]{3}{*}{ AMP } & \multirow[t]{3}{*}{2.0} & India & 23.0 \\
\hline & & & Shelys & 22.0 \\
\hline & & & Keko & 24.0 \\
\hline & CIPRO & 2.0 & India & 22.8 \\
\hline & \multirow[t]{3}{*}{ DICLO } & \multirow{3}{*}{2.0} & India & 16.0 \\
\hline & & & Shelys & 14.0 \\
\hline & & & Keko & 14.0 \\
\hline \multirow[t]{4}{*}{ CA } & \multirow[t]{2}{*}{ KETOC } & \multirow[t]{2}{*}{1.6} & Cyprus & 17.9 \\
\hline & & & Microlabs & 17.0 \\
\hline & NYST & 0,08 & Cyprus & 11.3 \\
\hline & FLUC & 1.2 & India & 17.6 \\
\hline \multirow[t]{4}{*}{$\mathrm{CN}$} & \multirow[t]{2}{*}{ KETOC } & \multirow[t]{2}{*}{1.6} & Cyprus & 18.3 \\
\hline & & & Microlabs & 17.5 \\
\hline & NYST & 0.08 & Cyprus & 11.2 \\
\hline & FLUC & 1.2 & India & 19.0 \\
\hline
\end{tabular}

$\mathrm{ST}=S$. aureus, $E C=E$.coli, $C A=C$.albicans, $C N=$ Cryptoccocus neoformans

Table 4: Mean zones of inhibition regardless of the tested microorganisms

\begin{tabular}{|l|l|l|l|}
\hline \multirow{2}{*}{ Drugs } & \multicolumn{3}{|c|}{ Zone of inhibition (mm) } \\
\cline { 2 - 4 } Amox & Mean & N & Std. Deviation \\
\hline Amp & 21.800 & 5 & .9189 \\
\hline Cipro & 22.800 & 5 & 1.5492 \\
\hline Diclox & 14.500 & 5 & 1.0328 \\
\hline Ketoco & 17.583 & 3 & 2.5495 \\
\hline Nysta & 11.250 & 3 & 1.0836 \\
\hline Flucon & 18.312 & 4 & .8660 \\
\hline Total & 18.275 & 30 & 1.8154 \\
\hline
\end{tabular}

Figure 1: Zl exhibited by various assayed drugs on test microbes

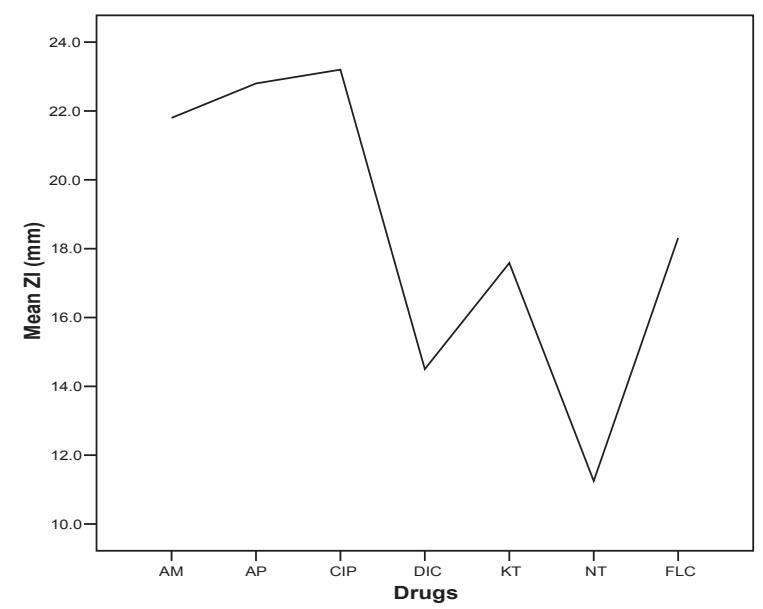


Figure2: Observed variability of results (ZI) of the tested drugs from different manufacturers

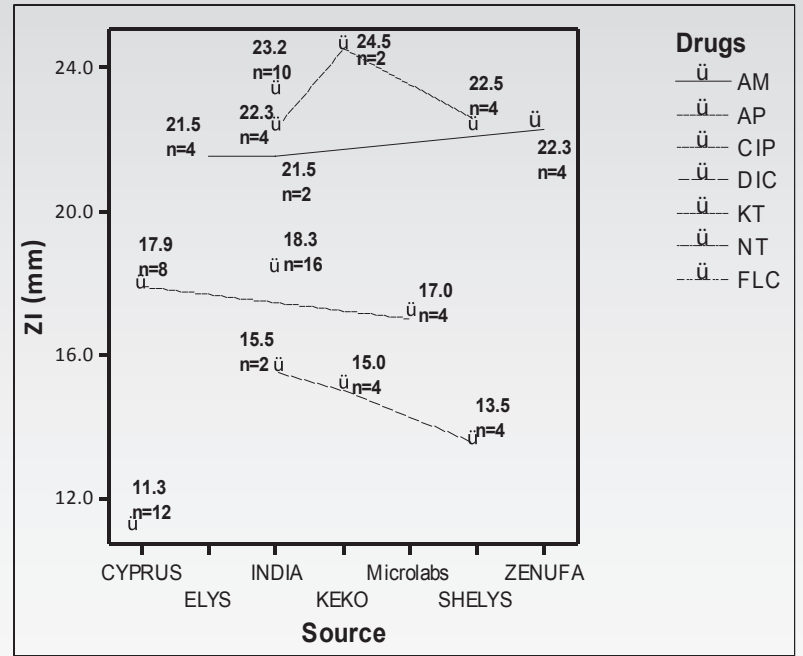

$\mathrm{AM}=$ amoxicillin, $\mathrm{AP}=$ ampicillin, $\mathrm{CIP}=$ ciprofloxacin, $\mathrm{DIC}=$ dicloxacilli $\mathrm{n}, \mathrm{KT}=$ ketoconazole

NT=nystatin, FLC=fluconazole

\section{DISCUSSION}

A total of 30 samples of different antimicrobial agents were collected and microbiologically analyzed in this study. Of those 20 were antibacterial agents, namely amoxicillin, ampicillin and dicloxacilin capsules; each one with a total of 5 capsules. Antifungal agents were composed of ketaconazole, nystatin and fluconazole tablets (Table 1).

Variability in ZI was observed among the tested drugs. Though the differences in terms of millimeters were not statistically significant $(p<0.05)$. However, this may have impact on the efficacy of the drugs against the microorganisms. For instance, ampicillin capsules from India, Shelly's and Keko differed among them by $3.5 \mathrm{~mm}$. Ampicillin capsules manufactured in India being the least efficacious (Table 3 )

For amoxicillin, ZI ranged between $21 \mathrm{~mm}$ (Elys) and $23 \mathrm{~mm}$ (Zenufa) against E.coli. Therefore a sample from Zenufa Laboratories was the most effective and a sample from Elys was the least effective, similarly a sample from Zenufa $(23 \mathrm{~mm})$ was the most effective against S.aureus and a sample from Elys $(21 \mathrm{~mm})$ was the least effective against S.aureus (Table 1). . For ciprofloxacin (India), the ZI ranged between $22 \mathrm{~mm}$ and $25 \mathrm{~mm}$ against both E.coli and S.aureus with the minimum effect $(22 \mathrm{~mm})$ being against E.coli and the maximum effect $(25 \mathrm{~mm})$ being against S.aureus. In case of dicloxacillin samples, a sample from Keko $(13 \mathrm{~mm})$ was the least effective against E.coli and a sample from India $(16 \mathrm{~mm})$ was the most effective against E.coli, while $\mathrm{ZI}$ between $15 \mathrm{~mm}$ (India) and $18 \mathrm{~mm}$ (Shelys) were exhibited by ampicillin samples against S.aureus (Table 1)

On the other hand ketoconazole exhibited $\mathrm{ZI}$ ranging between $16.5 \mathrm{~mm}$ and $19.0 \mathrm{~mm}$ against both Candida albicans and Cryptoccocus neoformans with the maximum effect being against Cryptoccocus neoformans and minimum effect being against C.albicans. Nystatin exhibited ZI ranging between $10 \mathrm{~mm}$ and $12 \mathrm{~mm}$ against both fungi. For the case of fluconazole, from $16.5 \mathrm{~mm}$ and $20.5 \mathrm{~mm}$ were exhibited against both fungi with the maximum effectiveness being against . neoformans (Table 1)

Generally speaking, regardless of the tested microorganisms, ciprofloxacin exhibited the largest mean radius (zone of inhibition) $(23.3 \mathrm{~mm}$ ) followed by Ampicillin $(22.8 \mathrm{~mm})$ as indicated on Table 4 and figure 1. Nystatin samples exhibited the least mean zone of inhibition.

The slight variations in effectiveness observed among the same class of antimicrobial agents (for example amoxicillin samples) may be due to differences in formula used by different manufacturers or inter batch variations or slight differences in active ingredients.

Figure 2 show the observed variability of results (ZI) of the tested drugs from different manufacturers. For instance, dicloxacillin from India, Keko and Sheyls varied from as low as 13.5 to $15.5 \mathrm{~mm}$; as well as ampicillin from Ellys, Zenufa and India varied from 21.5- $22.3 \mathrm{~mm}$, suggesting the existence of slight variations in efficacy among drugs from different manufacturers.

One of the drawbacks of this study was the lack of pure standard powder of each antimicrobial agent for preparing discs for comparison with the effects of the sample discs. 


\section{CONCLUSSION AND RECOMMENDATION}

The antimicrobial agents analyzed in this study have demonstrated substantial antimicrobial (antibacterial and antifungal) activities against the test microbes; an indicative of possession of active ingredients.

As far as the in vitro microbiological assays are concerned, the study's findings could not reveal any counterfeit drug.

However, further studies should be conducted to confirm the content specifications and other relevant parameters of each pharmaceutical preparation, because of lack of uniformity among the results in terms of Zl within the same class of drugs from different manufacturers.

\section{REFERENCES}

1. World Health Organization: counterfeit and substandard medicines: Fact sheet revise 2006.

2. Journal of Antimicrobial Chemotherapy-counterfeit or substandard antimicrobial drugs: A review of scientific evidence, 2007.

3. Wikipedia, the free encyclopedia, searched on $10^{\text {th }}$ December, 2008 at 10:30

4. World Health Organization-counterfeit and substandard medicines. 2004.

5. World Health Organization-counterfeit and substandard medicines. 2004. 